\title{
Eduardo Guimaraens e os novos
}

Regina Zilberman ${ }^{1}$

\begin{abstract}
Eduardo Guimaraens published three poems in the second volume of Orpheus, in 1915, among which we find "Under your eyes without tears." This poem appeared before in the magazine Fon-Fon!, from Rio de Janeiro, and then in The divine chimera, book released in 1916. The article examines the variants of that poem and their relationship with the rising new poetic in the years 1915 and 1916.
\end{abstract}

Keywords: Eduardo Guimaraens; Fon-Fon! Magazine; Orpheu; inovation.

Resumo: Eduardo Guimaraens publicou três poemas no segundo número de Orpheu, dentre os quais consta "Sob os teus olhos sem lágrimas". Esse poema apareceu antes na revista Fon-Fon!, do Rio de Janeiro, e depois em A divina quimera, livro lançado em 1916. Examinam-se as variantes do poema e suas relações com concepções de uma nova poética em ascensão entre 1915 e 1916.

Palavras-chave: Eduardo Guimaraens; Revista Fon-Fon!; Orpheu; inovação.

A Grande Esfinge do Egito sonha por este papel dentro... Escrevo - e ela aparece-me através da minha mão transparente E ao canto do papel erguem-se as pirâmides... Fernando Pessoa

À guisa de considerações iniciais

Orpheu, Exílio, Centauro e Portugal Futurista constituem o que se poderia chamar o "núcleo duro" das revistas do Modernismo em Portugal, já que veiculam a produção dos intelectuais que ocuparam a vanguarda daquele movimento. Assim, no primeiro volume de Orpheu, de março de 1915, encontram-se "O marinheiro", de Fernando Pessoa (1888-1935), e "Opiário" e "Ode triunfal", do heterônimo Alvaro de Campos; no segundo volume, de junho daquele ano, comparecem "Chuva oblíqua", conjunto de poemas interseccionistas assinados pelo ortônimo, e a caudalosa "Ode marítima”, de Alvaro de Campos. Por sua vez, Exílio, de 1916, que se propõe enquanto "Revista Mensal de Arte, Letras e Ciências", mas que não ultrapassou o primeiro número, conta com "Hora absurda", de Fernando Pessoa, que ainda redige uma resenha sobre o movimento sensacionista. Centauro, também de 1916, apresenta-se como "Revista Trimestral de Literatura", mas, como Exílio, limitou-se ao número inicial. Nela, Fernando Pessoa colocou os sonetos de "Passos da Cruz". Portugal Futurista, de 1917, foi menos otimista, ao considerar-se "Publicação eventual", mas, como as anteriores, ficou no volume inaugural. Fernando Pessoa e Alvaro de Campos são, outra vez, colaboradores do periódico, com a publicação, pelo primeiro, de "Ficções do interlúdio", e, pelo segundo, do "Ultimatum".

1 Docente dos Cursos de Graduação e Pós-Graduação - área de Literatura Portuguesa - UFRGS 
A esse "núcleo duro" de periódicos adeptos da modernidade estética correspondia um "núcleo duro" de artistas comprometidos com a renovação da arte em Portugal: na companhia de Fernando Pessoa, encontravam-se Mário de Sá Carneiro (1890-1916), Almada Negreiros (1893-1970) e Santa Rita Pintor (1889-1918).

Apenas dois poetas brasileiros, Ronald de Carvalho (1893-1935) e Eduardo Guimaraes (1892-1928), compartilham esse movimento, mas ficaram restritos aos dois números de Orpheu. Ronald de Carvalho publica poemas no volume inicial da revista, cuja direção dividiu com Luís de Montalvor (1892-1947). Eduardo Guimaraens apresenta três poemas no volume seguinte; como esse não foi seguido pelo lançamento do terceiro número, ainda que estivesse programado e em fase de impressão (SARAIVA, 2015), encerra-se aí a participação brasileira no andamento inicial do Modernismo em Portugal.

\section{Brasileiros em periódicos portugueses}

Não que brasileiros estivessem ausentes das páginas de revistas literárias lançadas em Portugal. A Águia, órgão da Renascença Portuguesa dirigido por Teixeira de Pascoaes (1877-1952) e onde Fernando Pessoa estampou ensaios (dois de seus mais famosos estudos sobre a poesia lusitana aparecem nos volumes 4, 5, 9, 11 e 12 daquele periódico, em 1912), versos e textos em prosa, como "Floresta do alheamento", assinado por Bernardo Soares, deu lugar a muitos contos e fantasias de Coelho Neto (1864-1934), entre outros autores brasileiros da época. Atântida, Mensário Artístico, Literário e Social para Portugal e Brasil, nascida em 1915, poucos meses depois do segundo número de Orpheu, tinha intuito binacional explícito, desde o título e a direção compartida entre o português João de Barros (1881-1960) e o carioca João do Rio (1881-1921), até o duplo financiamento, já que era patrocinada pelo Ministério das Relações Exteriores, no Brasil, e o Ministério dos Estrangeiros e do Fomento, em Portugal. Entre os colaboradores de Atlântida, encontram-se Afrânio Peixoto (1876-1947), Júlia Lopes de Almeida (1862-1934) e Graça Aranha (1868-1931), entre outros então membros da Academia Brasileira de Letras e representantes da literatura produzida no país nas primeiras décadas do século XX. Brasil - Portugal, fundada em 1899, com periodicidade quinzenal até 1914, era outro órgão da imprensa que facultava a difusão de escritores brasileiros para leitores lusitanos, constando entre os colaboradores Júlia Lopes de Almeida, Olavo Bilac (1865-1918) e Valentim Magalhães (1859-1903), para lembrar os mais frequentes.

Logo, a presença de Ronald de Carvalho e de Eduardo Guimaraens entre os poetas que participaram dos dois números de Orpheu não surpreende, por um lado; mas surpreende por outro: não se verifica subsequentemente a presença deles ou de outro representante de sua geração nos periódicos que fizeram avançar a proposta de modernização das Letras em Portugal. Não que Ronald de Carvalho, então com 22 anos, e Eduardo Guimaraens, com 23 anos, não correspondessem à nova geração de escritores brasileiros, nascidos já sob a vigência do regime republicano, implantado em 1889. Eram até mais jovens que Oswald de Andrade, nascido em 1890 (falecido em 1954), e coetâneos de Mário de Andrade (1893-1945); mas esses talvez não tenham reconhecido o experimentalismo para onde se dirigiam os parceiros portugueses de Orpheu, na época em que essa revista foi publicada. E, quando optaram, em 1921, pela organização da Semana de Arte Moderna, realizada em fevereiro de 1922, o grupo de Fernando Pessoa, já desfalcado de Mário de Sá Carneiro e de Santa Rita-Pintor, tomava outros rumos, menos afinados com o Futurismo ou com o nacionalismo para onde então se orientavam os paulistas. Decorre daí talvez a carência de 
intercâmbio entre os líderes das propostas renovadoras das artes em Portugal e no Brasil, associada também à provável falta de circulação das obras daqueles autores que tiveram oportunidade de veicular seus textos na pioneira Orpheu.

Ronald de Carvalho e Eduardo Guimaraens eram, por outro lado, parceiros em outra publicação - a carioca Fon-Fon! (1907-1958), onde igualmente atuou por um tempo, à época em que residiu no Rio de Janeiro, Luís da Silva Ramos, depois Luís Montalvor, co-diretor de Orpheu em seu primeiro volume e diretor de Centauro, em seu primeiro e único volume. ${ }^{2}$

\section{Eduardo Guimaraens em Fon-Fon!}

É nas páginas daquela revista que Eduardo Guimaraens. em 25 de outubro de 1913, apresenta, na seção "Atualidade literária", o artigo, que tem o formato de uma carta, denominado "Palavras a um novo". O título parece dialogar com "A poesia dos novos", artigo publicado em 6 de outubro de 1912, no jornal A Época, do Rio de Janeiro, em que José Oiticica (1882-1957) examina a poesia de Augusto dos Anjos (1884-1914). Ainda que não se mostre muito entusiasmado com o escritor paraibano, Oiticica reconhece em seus versos "a qualidade essencial ao poeta novo" (OITICICA, 2012, p. 7, col. 1). Apesar do elogio, chama a atenção para os defeitos da obra, relacionados ao vocabulário, metrificação e expressão de ideias, marcadas pelo "pessimismo doentio e insincero" (OITICICA, 2012, p. 7, col. 2). Conclui que ao poeta cabe superar aqueles defeitos, para deixar de constituir apenas uma promessa literária.

Em seu artigo, Eduardo Guimaraens não endossa a posição de Oiticica, enfatizando que "toda teoria estética, quando se trata de fazer arte, arte que seja bela, arte que fique, arte artística, é inútil, absurda, supérflua" (GUIMARAENS, 1913, p. 39, col. 1). Portanto, conclui o poeta, "em arte, não há teoria possível, não há ideias centrais dominantes, científicas ou não, a obedecer", já que "tudo é alma, emoção, instinto" (GUIMARAENS, 1913, p. 39, col. 1). Rebatendo os conceitos e as sugestões dadas por Oiticica, acaba, ele mesmo, por oferecer um conselho a seu interlocutor, considerando que esse almeja "dar um rumo original e novo à [s]ua poesia":

Quanto aos conselhos, é simples: [...] Eu te direi: vive, ama, sofre. Sonha, acima de tudo! Sê o mais possível tu mesmo: porque a maior parte do mal está em aniquilar a noção do Eu. Toda a tua poesia será imediatamente original. Tu saberás então que a arte, a Verdadeira, única por conseguinte, só pode ser pessoal, mas desse pessoalismo comunicativo que põe a alma face a face com a alma. (GUIMARAENS, 1913, p. 39, col. 2)

$\mathrm{Na}$ formulação de Guimaraens, a poesia emerge do talento e das vivências interiores do poeta, que será tanto melhor quanto mais esse deixar vazar espontaneamente seus sonhos. Só assim será ele mesmo, sem interferências teóricas ou programas ideológicos. Só assim também ele se configurará enquanto um "novo", termo que não corresponde, nas palavras de Guimaraens, ao moderno, mas que, de todo modo, aponta para o que ainda não se apresentava na poesia brasileira, a se julgar pela rejeição das correntes então vigentes, como o Parnasianismo, o Simbolismo e o cientificismo.

2 Sobre Fon-Fon!, cf. BRAGA (2008) e SOUSA (2015). 


\title{
Conexão Letras
}

\section{Eduardo Guimaraens, de Fon-Fon! a Orpheu}

Desde 1912, Eduardo Guimaraens publicava poemas em Fon-Fon!, após ter colaborado em A Careta (1909-1964), também do Rio de Janeiro. Os textos em verso ou em prosa em Fon-Fon! são mais frequentes, sucedendo muitos deles ao que o escritor manifestara em "Palavras a um novo". Destaque-se, dentre os que se seguiram àquela crônica em forma de carta, o poema "Sob os teus olhos sem lágrimas" (GUIMARAENS, 1915, p. 42, col. 2), de fevereiro de 1915, pois é o texto que, meses depois, fará parte do segundo volume de Orpheu, acompanhando outros dois textos, "Sobre o cisne de Stéphane Mallarmé" e "Folhas mortas":

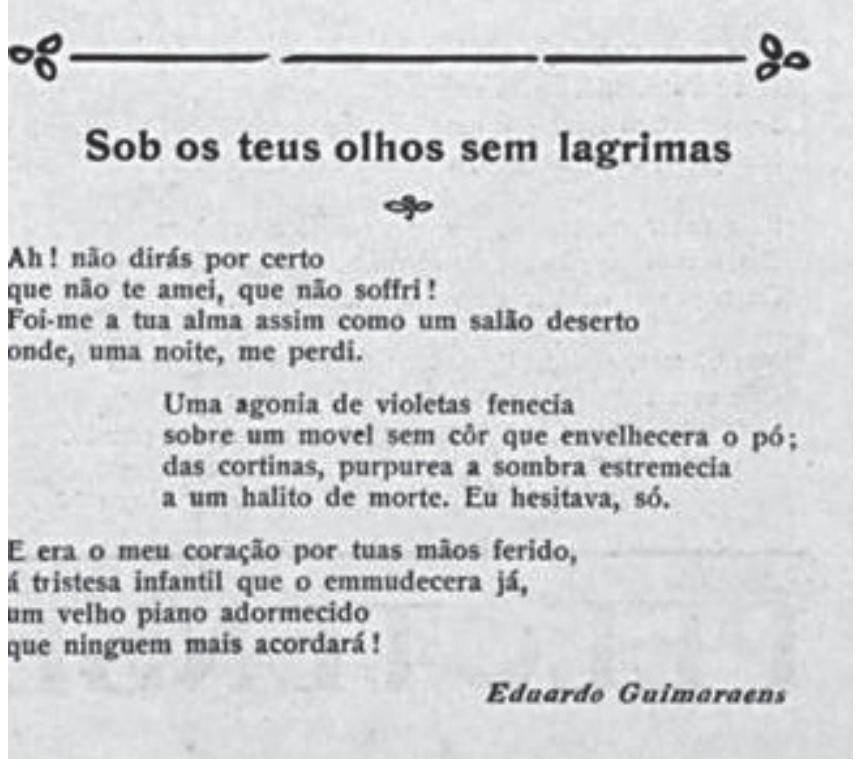

Esses versos aparecem em meio às seções destinadas a "Notas Mundanas" e "Aniversários", dividindo o espaço gráfico ainda com a crônica de cunho humorístico, "O baunilhismo", assinada por Samuel Tristão, um dos pseudônimos adotados por Alvaro Moreyra (1888-1964) na revista carioca.

Em Orpheu, o poema apresenta os seguintes versos: ${ }^{3}$

\author{
Ah! não dirás por certo \\ que não te amei, que não sofri! \\ Foi-me a tua alma assim como um salão deserto \\ onde, uma noite, me perdi. \\ Um ramo de violetas fenecia \\ em cada móvel amortalhado pelo pó; \\ a púrpura das cortinas, rubra, estremecia \\ presa a cada janela. Eu hesitava, só.
}

3 GUIMARÃES, Eduardo. Sob os teus olhos sem lágrimas. Orpheu. Revista Trimestral de Literatura. Versão on line: http://www.gutenberg.org/ebooks/23621. Acesso em 25 de fevereiro de 2015. Cf. a transcrição do poema em SARAIVA, 2004, p. 117, e SARAIVA, 2015, p. 113. 
- E era meu coração, por ti quase ferido,

a dúvida infantil que o emudecera já,

um velho piano adormecido

que ninguém mais acordará.

O poema retorna, sem título, como o poema 14 da primeira parte de A divina quimera (GUIMARAENS, 1944, p. 147): ${ }^{4}$

Ah, não dirás, por certo,

que não te amei, que não sofri!

Foi-me a tua alma assim como um salão deserto

onde uma noite, me perdi,

Sobre o escuro tapete uma rosa morria

que deixara cair, sem pena a tua mão.

Das cortinas, purpúrea, a sombra estremecia...

Havia em cada espelho uma recordação.

- E era o meu coração ardente e dolorido,

sob a dor infantil que o emudecera já,

um velho piano adormecido

que ninguém mais acordará!

Em Modernismo brasileiro e Modernismo português (SARAIVA, 2004, p. 117), Arnaldo Saraiva contrapõe as duas versões do poema publicadas respectivamente em Orpheu e $A$ divina quimera. ${ }^{5}$ Acrescenta-se, na quadro abaixo, a versão original, que apareceu em fevereiro de 1915, em Fon-Fon!, sugerida por Arnaldo Saraiva, que comenta em "O Orpheu e o Brasil":

É estranho que a colaboração dos brasileiros no Orpheu, e em especial a de Eduardo Guimaraens, não tenha interessado quase nenhum dos muitos estudiosos portugueses e brasileiros da revista. Isso explica que ninguém se tenha ainda dado conta de que pelo menos um dos poemas de Eduardo Guimaraens já estava publicado quando Orpheu 2 saiu. Trata-se exatamente de "Sob os teus olhos sem lágrimas", publicado na Fon-Fon! de 27 de fevereiro de 1915 - quer dizer, um mês antes do aparecimento de Orpheu 1. (SARAIVA, 2015, p. 115)

No quadro a seguir, reproduzem-se as três variantes do poema, com destaque, em negrito e itálico, dos versos que sofreram alterações:

Sob os teus olhos sem lágrimas

\begin{tabular}{|l|l|l|l|}
\hline & \multicolumn{1}{|c|}{ Fon-Fon! [1915] } & \multicolumn{1}{c|}{ Orpheu [1915] } & \multicolumn{1}{c|}{ A divina quimera [1916] } \\
\hline Estrofe 1 & Ah! não me dirás por certo & Ah! não dirás por certo & Ah, não dirás, por certo, \\
\hline & que não te amei, que não sofri! & que não te amei, que não sofri! & que não te amei, que não sofri! \\
\hline & $\begin{array}{l}\text { Foi-me a tua alma assim como } \\
\text { um salão deserto }\end{array}$ & $\begin{array}{l}\text { Foi-me a tua alma assim como um } \\
\text { salão deserto }\end{array}$ & $\begin{array}{l}\text { Foi-me a tua alma assim como um } \\
\text { salão deserto }\end{array}$ \\
\hline & onde, uma noite me perdi. & onde, uma noite, me perdi. & onde uma noite, me perdi, \\
\hline
\end{tabular}

4 O título original - "Sob os teus olhos sem lágrimas" - nomeia o soneto que pertence à coleção "Poemas à bem amada". Precedido por uma epígrafe extraída de Stéphane Mallarme, "Une rose dans lês ténèbres", escreve o poeta: "Não porque a noite, de astros pura, / traga ao meu riso este ar dolente / de um trovador convalescente, / lembro-te, calmo e sem tortura, // Mas, porque à luz, que transfigura, / constantemente, eternamente, / esta paisagem da alma ardente, / outra surgiu mais lenta e obscura. // Outra surgiu que mostra em cada / canto uma planta misteriosa, / um lírio negro, um flox tristonho: // E esta dor mortal e sagrada / que floresceu, como uma rosa, / do mais profundo do meu sonho!" (GUIMARAENS, 1944, p. 205).

5 Cf. também o contraponto em SARAIVA, 2015. 


\begin{tabular}{|l|l|l|l|}
\hline Estrofe 2 & $\begin{array}{l}\text { Uma agonia de violetas fe- } \\
\text { necia }\end{array}$ & Um ramo de violetasfenecia & $\begin{array}{l}\text { Sobre o escuro tapete uma rosa } \\
\text { morria }\end{array}$ \\
\hline & $\begin{array}{l}\text { sobre um móvel sem cor que } \\
\text { envelhecera o pó; }\end{array}$ & $\begin{array}{l}\text { em cada móvel amortalhado pelo } \\
\text { pó }\end{array}$ & $\begin{array}{l}\text { que deixara cair, sem pena a tua } \\
\text { mão. }\end{array}$ \\
\hline & $\begin{array}{l}\text { dascortinas, purpúrea a som- } \\
\text { bra estremecia }\end{array}$ & $\begin{array}{l}\text { a púrpura das cortinas, rubra, } \\
\text { estremecia }\end{array}$ & $\begin{array}{l}\text { Das cortinas, purpúrea, a sombra } \\
\text { estremecia... }\end{array}$ \\
\hline & $\begin{array}{l}\text { a um hálito de morte. Eu } \\
\text { hesitava, só. }\end{array}$ & presa a cada janela. Eu hesitava, só. & $\begin{array}{l}\text { Havia em cada espelho uma recor- } \\
\text { dação. }\end{array}$ \\
\hline Estrofe 3 3 & $\begin{array}{l}\text { E era o meu coração por tuas } \\
\text { mãos ferido, }\end{array}$ & $\begin{array}{l}\text { E era meu coração, por ti quase } \\
\text { ferido }\end{array}$ & $\begin{array}{l}\text { E era o meu coração ardente e } \\
\text { dolorido, }\end{array}$ \\
\hline & $\begin{array}{l}\text { a tristeza infantil que o emu- } \\
\text { decera já, }\end{array}$ & $\begin{array}{l}\text { a dúvida infantil que o emudecera } \\
\text { já, }\end{array}$ & soba dor infantilqueo omudecera já, \\
\hline & um velho piano adormecido & um velho piano adormecido & um velho piano adormecido \\
\hline & que ninguém mais acordará! & que ninguém mais acordará. & que ninguém mais acordará! \\
\hline
\end{tabular}

Alguns meses separam a primeira e a segunda versão do poema, e outros tantos meses, a segunda e a terceira formulação, sugerindo que, nesse curto período, o poeta dedicou-se com intensidade ao aperfeiçoamento de seu texto. Ele manteve intacta a primeira estrofe, mas a segunda e os versos iniciais da terceira foram sensivelmente alterados. Esses seis versos correspondem a cinquenta por cento do conjunto de doze versos e, por sua disposição, ocupam seu miolo.

A estrofe de abertura estabelece, de imediato, o diálogo entre o sujeito lírico, que, em duas negativas, contradiz seu interlocutor, não identificado, asseverando simultaneamente seu amor e seu sofrimento. Por meio de uma oração afirmativa, define a alma do ser amado por meio de uma comparação espacial - "um salão deserto" em que ele teria se perdido - e uma ambientação temporal - a perda dar-se-ia à noite ou confundir-se-ia com o clima noturno, logo, sombrio.

A segunda estrofe é a que passa por alterações substanciais, relativas:

a) à flor que fenece, originalmente "violetas", depois, "um ramo" delas, enfim "uma rosa";

b) ao lugar onde a flor se encontrava: um móvel envelhecido ou empoeirado nas duas variantes preliminares, um tapete escuro na versão de $A$ divina quimera;

c) o reaparecimento do interlocutor, que deixara cair, impiedosamente, a flor, razão possível da morte daquele ser (ou, metaforicamente, da morte do interlocutor);

Os dois primeiros versos da segunda estrofe apontam, nas transformações por que passam, um trânsito de uma imagem antropomorfizada - a violeta em agonia - para uma visão realista - as violetas que fenecem -, substituída ao final pela rosa que cai da mão do interlocutor. A morte, originalmente sugerida pelas violetas agonizantes, migra para a rosa, que se apresenta como signo da morte ou desinteresse do interlocutor, provavelmente uma mulher.

O terceiro verso modifica-se da primeira para a segunda versão, para retornar, quase idêntico, à forma original. Em A divina quimera, ele inicia nova oração, enquanto que, nas expressões anteriores, dava continuidade ao período começado pelo primeiro verso da estrofe. $\mathrm{O}$ abandono da formulação proposta no verso 3 da estrofe 2 deve-se talvez à redundância decorrente da nomeação da cor - "púrpura" e "rubra" - das cortinas. Ao alterar 
o teor do verso, a "sombra" volta a ser o sujeito do verbo estremecer, que, originalmente, era a reação ao "hálito de morte", resposta que desaparece na última redação do verso. Outra vez a antropomorfização, advinda da menção ao "hálito da morte", é deixada de lado; e o sujeito lírico, mencionado em Fon-Fon! e em Orpheu, retira-se da cena, pois o verso 4 da estrofe 2 prefere transferir para o espelho, que reflete o cenário, a reverberação dos indivíduos que transitaram pelo espaço fechado do "salão deserto" mencionado no primeiro quarteto.

As mudanças operadas no verso 1 da estrofe 3 são igualmente significativas: o "coração" do sujeito lírico é mantido nas três versões, mas o responsável pelo seu sofrimento apaga-se: as "mãos" do interlocutor são suprimidas e, depois, não são mais mencionadas, extinguindo-se igualmente a referência a essa alteridade que provoca a dor daquele que se expressa em primeira pessoa. O coração, por sua vez, a se crer no que propõe o verso seguinte, já passara por um enclausuramento - a mudez, reiterada nas três variantes, mas suas causas modificam-se: a "tristeza infantil" é substituída pela "dúvida infantil", convertendo-se enfim em "dor infantil", opção que replica o que fora antes exposto por meio do adjetivo "dolorido". Nas três alternativas, o esforço em não adulterar a metrificação do verso e, ao mesmo tempo, não perder de vista a rima com o adjetivo "adormecido", vocábulo que guarda em sua intimidade o substantivo "dor", tão importante no contexto do poema.

Ainda que recuse, em "Palavras a um novo", o formalismo ou a teoria estética enquanto um valor em si mesmo, Eduardo Guimaraens mostra-se, em "Sob os teus olhos sem lágrimas", um poeta cuidadoso, que não se satisfaz com a primeira versão de um poema. Meticuloso, ele experimenta alternativas e variantes, na busca da melhor formulação. Orpheu representou a hipótese de testar o estágio que alcançara seu texto, mas, provavelmente insatisfeito, continuou a conferir atenção a seus versos, almejando alcançar um resultado superior.

O título do poema antecipa seu tema - os "olhos sem lágrimas" são também olhos sem vida, atributo do interlocutor a quem o eu lírico se dirige. O vazio sugerido pelo título se alarga, quando se alude ao "salão deserto" em que o sujeito se perde em uma noite. A morte é referida nas duas versões iniciais do texto, mas o poeta não mais a menciona, quando o publica em livro, em 1916; transforma-a em sugestão, que se amplia nas indicações ao "piano adormecido / que ninguém mais acordará", aludindo ao silêncio em que mergulha o eu lírico.

O cenário, desprovido de seres humanos, antropomorfiza-se por meio dos objetos humanizados - "agonia das violetas", na primeira versão, "piano adormecido" nas três variantes - mas mesmo essas alternativas acabam por comprovar, ao final, a ausência de qualquer tipo de vida. A passagem, porém, faculta ao poeta intensificar as sugestões, como se observou antes, e, na alusão ao dormir e acordar, introduzir a atmosfera onírica prevista em suas anotações sobre a nova poesia: "Sonha, acima de tudo!", escreveu ele na crônica publicada meses antes em Fon-Fon!

O sonho está presente de modo explícito em outro dos poemas que Guimaraens publicou em Orpheu, denominado "Sobre o Cisne de Stéphane Mallarmé", que Mansueto Bernardi (1888-1966), responsável pela edição completa de A divina quimera, inclui em Estâncias de um peregrino (GUIMARAENS, 1944, p. 341):

Um Sonho existe em nós como um cisne num lago de água profunda e clara e em cujo fundo existe outro cisne alvo e triste, e ainda mais alvo e triste que a sua forma real de um tom dolente e vago. 
Nada: e os gestos que tem, de carícia e de afago, lembram da imagem tênue, onde a tristeza insiste por ser mais alva, a graça inversa em que consiste a dolente mudez de um espelho pressago.

Um cisne existe em nós como um sonho de calma, plácido, um cisne branco e triste, longo e lasso e puro, sobre a face oculta de nossa alma.

E a sua imagem lembra a imagem de um destino de pureza e de amor que segue, passo a passo, este sonho imortal como um cisne divino!

Nesses versos, aparece igualmente a alusão ao espelho, que desdobra as imagens e confere-lhe profundidade; por isso, o sonho, corporificado no "cisne", reproduz-se em "outro cisne", ainda mais triste. O espelho é mencionado apenas na segunda estrofe, "pressago", anunciando algo indefinido para além dele, o que sugere os níveis acolá do meramente referencial não apenas das imagens propostas, mas de seus significados concretos. Por isso, o terceto final devolve as imagens para o universo do sonho sem fronteiras, "imortal".

$\mathrm{O}$ sonho é igualmente uma referência constante no primeiro volume de Orpheu. $\mathrm{Na}$ "Introdução" com que abre a revista, Luís de Montalvor refere-se ao projeto que congrega os autores ali reunidos: eles "esperam ansiosos e sonham nalguma coisa que lhes falta, - do que resulta uma procura estética de permutas: os que nos procuram e os que nós esperamos...". 6

É, porém, em $O$ marinheiro, o drama estático que Fernando Pessoa divulgou naquele volume, que o sonho assume o primeiro plano do discurso. As três veladoras, diante do caixão "com uma donzela, de branco", 7 expressam seu desejo escapista por meio do sonho de uma delas, que as leva imaginariamente para longe. Assim, depois de recordarem o passado que recusam, encontram na fantasia um modo de fugir do ambiente opressivo em que se encontram.

Fernando Pessoa confirma a atmosfera onírica exposta no drama estático no segundo volume de Orpheu, ao publicar o poema interseccionista "Chuva oblíqua", ${ }^{8}$ cuja abertura poderia constituir a epígrafe de $O$ marinheiro:

Atravessa esta paisagem o meu sonho d'um porto infinito

E a cor das flores é transparente de as velas de grandes navios

Que largam do cais arrastando nas águas por sombra Os vultos ao sol daquelas árvores antigas...

Mais adiante, ainda na primeira parte, o eu lírico confessa: "Não sei quem me sonho...", declaração que se relaciona ao desejo poético de dar vazão à proposta interseccionista de cruzar elementos figurativos e sensoriais de ordem diversa. É o sonho, enquanto linguagem, que se mostra capaz de romper a lógica linear do pensamento ou comparativa da imagem. Por isso, cabe colocá-lo em primeiro plano, ainda que não represente todas as possibilidades de expressividade literária.

Ainda que a obra $A$ interpretação dos sonhos, de Sigmund Freud (1856-1939), já

6 MONTALVOR, Luís de. Introdução. Orpheu. Revista Trimestral de Literatura. Versão on line: http://www. gutenberg.org/ebooks/23621. Acesso em 25 de fevereiro de 2015.

7 PESSOA, Fernando. O marinheiro. Drama estático em um quadro. Orpheu. Revista Trimestral de Literatura. Versão on line: http://www.gutenberg.org/ebooks/23621. Acesso em 25 de fevereiro de 2015.

8 PESSOA, Fernando. Chuva oblíqua. Poemas interseccionistas. Orpheu. Revista Trimestral de Literatura. Versão on line: http://www.gutenberg.org/ebooks/23621. Acesso em 25 de fevereiro de 2015. 
estivesse publicada desde 1899 e fosse provavelmente conhecida por muitos intelectuais no início do século XX, pode-se supor que a valorização, pelos poetas mencionados, da linguagem onírica, incluindo sua sintaxe alógica, proviesse dos princípios simbolistas. Para a então ascendente Psicanálise, o sonho exibia, em seu conteúdo latente, desejos reprimidos, frustrações e, ao fim e ao cabo, a irresolução do desejo edípico pela mãe. $\mathrm{O}$ sonho incorporado pelos poetas apresentava-se desprovido daqueles componentes eróticos, ainda que se possa rastrear, para não perder de vista os versos de Eduardo Guimaraens, na "tristeza infantil", ou na "dúvida infantil", ou ainda na "dor infantil" que emudece, a possível insatisfação de um desejo que remonta à infância e, eventualmente, à figura materna.

Ainda assim, quando os simbolistas e os poetas das primeiras décadas do século XX referem-se ao sonho e mencionam-no direta ou indiretamente em seus versos, não o fazem para dar vazão ao inconsciente. Mais próximo de seus objetivos é o perspectiva escapista que Fernando Pessoa coloca na boca das veladoras, em $O$ marinheiro. O sonho possibilitaria o acesso a outro mundo, ainda que, concretamente, inacessível. Henrik Ibsen (18281906), em "Quando despertarmos de entre os mortos", sua derradeira peça para o teatro, expõe a ambiente espectral propiciada pela imaginação que talvez tenha impressionado Fernando Pessoa e motivado-o a escrever $O$ marinheiro. Nas duas obras, trata-se de uma inconformidade com o mundo burguês ou com um passado comezinho, como no caso das jovens que protagonizam o drama publicado em Orpheu.

\section{A título de fechamento}

Ao dirigir suas "Palavras a um novo", Eduardo Guimaraens considera o Simbolismo um movimento do século XIX, pertencente, pois, ao passado, tempo que ele, tal como as veladoras de $O$ marinheiro, rejeita: "Tu sabes bem o que resta do Romantismo, da corrente parnasiana, do movimento simbolista. Foram estes, entretanto, os três grandes estados da poesia do século XIX. Que resta deles: alguns grandes livros, alguns grandes poetas.” (GUIMARAENS, 1913, p. 39, col. 1).

É fácil concluir que Eduardo Guimaraens julgava-se um "novo", cuja obra não se enquadraria na tendência simbolista, vertente que joga para o passado. Mal sabia ele que os manuais de história da literatura brasileira, na esteira do estudo de Andrade Muricy (MURICY, 1973), sobre o panorama da poesia simbolista brasileira, aí o incluiriam. Se perguntado, talvez o escritor considerasse que os simbolistas tinham sido representados, no Brasil, por Cruz e Souza (1861-1898) e Alphonsus de Guimaraens (1870-1921) - a quem homenageia ao reproduzir a grafia do sobrenome - que pertenciam a uma geração anterior.

Por isso, identificou-se com o movimento de Orpheu, aconselhado provavelmente por seus dois parceiros de Fon-Fon!, Ronald de Carvalho e Luís de Montalvor. Se teve a oportunidade de ler o primeiro volume daquele periódico, percebeu que pertencia àquele grupo de sonhadores que almejava renovar a poesia em língua portuguesa.

Não deve ter-se arrependido de colaborar com o segundo volume, nem de dar prosseguimento ao trabalho sobre seus poemas inovadores, de que "Sob os teus olhos sem lágrimas" é um exemplo notável.

\section{Referências}

BRAGA, Regina Stela (ed.) Fon-Fon! Buzinando a Modernidade. Rio de Janeiro: Secretaria Especial de Comunicação Social, 2008. 


\section{Conexão Letras}

GUIMARAENS, Eduardo. Palavras a um novo. Fon-Fon!. Rio de Janeiro, 25 de outubro de 1913.

GUIMARAENS, Eduardo. Sob os teus olhos sem lágrimas. Fon-Fon!. Rio de Janeiro, 27 de fevereiro de 1915.

GUIMARÃES, Eduardo. Sob os teus olhos sem lágrimas. Orpheu. Revista Trimestral de Literatura. Versão on line: http://www.gutenberg.org/ebooks/23621. Acesso em 25 de fevereiro de 2015.

GUIMARAENS, Eduardo. A divina quimera. Edição definitiva com prefácio de Mansueto Bernardo. Porto Alegre, Globo, 1944.

MONTALVOR, Luís de. Introdução. Orpheu. Revista Trimestral de Literatura. Versão on line: http://www.gutenberg.org/ebooks/23621. Acesso em 25 de fevereiro de 2015. MURICY, Andrade. Panorama do movimento simbolista brasileiro. 2. ed. Brasília: Ministério de Educação e Cultura, 1973. 2v.

OITICICA, José. A poesia dos novos. A Época, Rio de Janeiro, 6 de outubro de 1912. PESSOA, Fernando. O marinheiro. Drama estático em um quadro. Orpheu. Revista Trimestral de Literatura. Versão on line: http://www.gutenberg.org/ebooks/23621. Acesso em 25 de fevereiro de 2015.

PESSOA, Fernando. Chuva oblíqua. Poemas interseccionistas. Orpheu. Revista Trimestral de Literatura. Versão on line: http://www.gutenberg.org/ebooks/23621. Acesso em 25 de fevereiro de 2015.

SARAIVA, Arnaldo. Modernismo brasileiro e Modernismo português. Subsídios para o seu estudo e para a história de suas relações. Campinas: Editora Unicamp, 2004. SARAIVA, Arnaldo. Os órfãos de Orpheu. Porto: Fundação Eng. Antônio de Almeida, 2015.

SOUSA, Rui. Os bastidores brasileiros de Orpheu: páginas da revista Fon-Fon! (19121914). Pessoa Plural. Revista de Estudos Pessoanos, n. 7, 2015. p. 160-181. 